\title{
Inhibitory kappa B kinase- $\beta$ is a target for specific nuclear factor kappa B-mediated delayed cardioprotection
}

\author{
Nancy C. Moss, MD, ${ }^{a}$ Ru-Hang Tang, PhD, ${ }^{\text {a }}$ Monte Willis, MD, PhD, ${ }^{b}$ William E. Stansfield, MD, ${ }^{\text {a }}$ Albert S. Baldwin, PhD, \\ and Craig H. Selzman, MD
}

\begin{abstract}
Objective: Myocardial ischemia/reperfusion injury remains a vexing problem. Translating experimental strategies that deliver protective agents before the ischemic insult limits clinical applicability. We targeted 2 proteins in the nuclear factor- $\kappa \mathrm{B}$ pathway, inhibitory kappa B kinase- $\beta$, and $26 \mathrm{~S}$ cardiac proteasome to determine their cardioprotective effects when delivered during reperfusion.
\end{abstract}

\begin{abstract}
Methods: C57BL/6 mice underwent left anterior descending artery occlusion for 30 minutes. An inhibitory kappa B kinase- $\beta$ inhibitor (Compound A), a proteasome inhibitor (PS-519), or vehicle was administered at left anterior descending artery release or 2 hours afterward. Infarct size was analyzed 24 hours later. Pressure-volume loops were performed at 72 hours. Serum and left ventricular tissue were collected 1 hour after injury to examine protein expression by enzyme-linked immunosorbent assay and Western blot.
\end{abstract}

Results: Inhibitory kappa B kinase- $\beta$ and proteasome inhibition significantly attenuated infarct size and preserved ejection fraction compared with the vehicle groups. When delivered even 2 hours after reperfusion, Compound A, but not PS-519, still decreased infarct size in mice. Finally, when delivered at reperfusion, successful inhibition of phosphorylated-p65 and decreased interleukin- 6 and tumor necrosis factor- $\alpha$ levels occurred in mice given the inhibitory kappa B kinase- $\beta$ inhibitor, but not in mice with proteasome inhibition.

Conclusion: Although inhibitory kappa B kinase- $\beta$ and proteasome inhibition at reperfusion attenuated infarct size after acute ischemia/reperfusion, only inhibitory kappa B kinase- $\beta$ inhibition provided cardioprotection through specific suppression of nuclear factor $-\kappa \mathrm{B}$ signaling. This feature of highly targeted nuclear factor- $\kappa \mathrm{B}$ inhibition might account for its delayed protective effects, providing a clinically relevant option for treating myocardial ischemia/reperfusion associated with unknown periods of ischemia and reperfusion as seen in cardiac surgery and acute coronary syndromes.

Nuclear factor-kappa B $(\mathrm{NF}-\kappa \mathrm{B})$ is a transcription factor that regulates proinflammatory cytokine expression and is activated in cardiac tissue after ischemia/reperfusion (I/R) injury. ${ }^{1}$ Several common cardiovascular drugs that have nonspecific inhibitory $\mathrm{NF}-\kappa \mathrm{B}$ activity are a routine part of our armamentarium, including statins, aspirin, and adenosine. $^{2-4}$ Although strategies aimed at NF- $\kappa \mathrm{B}$ inhibition have been shown to decrease infarct size and preserve function in animal models of myocardial $\mathrm{I} / \mathrm{R},{ }^{5,6}$ the majority of experimental models study interventions before the actual ischemic insult. A treatment targeting $\mathrm{NF}-\kappa \mathrm{B}$ that is efficacious when delivered before injury may not be effective or may function differently when administered

From the Departments of Surgery, ${ }^{\mathrm{a}}$ Pathology, ${ }^{\mathrm{b}}$ and Biology, ${ }^{\mathrm{c}}$ University of North Carolina, Chapel Hill, North Carolina.

The Thoracic Surgery Foundation for Research and Education (W.E.S.), National Institutes of Health (A.S.B.), and American College of Surgeons (C.H.S.) provided funding.

Presented at the C. Walton Lillehei Resident Forum, 88th Annual Meeting of the AATS, San Diego, California, May 10 to 14, 2008.

Received for publication April 1, 2008; revisions received June 25, 2008; accepted for publication July 26, 2008.

Address for reprints: Craig H. Selzman, MD, Division of Cardiothoracic Surgery, University of North Carolina at Chapel Hill, 3040 Burnett-Womack Bldg, CB 7065,

Chapel Hill, NC 27599-7065 (E-mail: Selzman@med.unc.edu).

J Thorac Cardiovasc Surg 2008;136:1274-9

$0022-5223 / \$ 34.00$

Copyright (c) 2008 by The American Association for Thoracic Surgery

doi: $10.1016 /$ j.jtcvs.2008.07.041 at a later point in time, because periods of ischemia are not predictable (ie, patients with acute coronary syndrome). Furthermore, patients with controlled I/R associated with cardiac surgery can have disparate ischemic times. The only physiologic phenomenon clinicians can reproducibly rely on is reperfusion. Thus, NF- $\kappa \mathrm{B}$ inhibition before an ischemic insult creates a temporal disconnect between injury and therapy. ${ }^{7}$

$\mathrm{NF}-\kappa \mathrm{B}$, in its heterodimer form of the p50 and p65 subunits, remains inactive in the cell cytoplasm while bound to the repressor protein, inhibitory kappa-B alpha $(\mathrm{I} \kappa \mathrm{B} \alpha)$. After cardiac reperfusion injury, reactive oxygen species unleash a kinase cascade that ultimately activates the inhibitory kappa-B kinase (IKK) complex. In particular, activation of the IKK $\beta$ subunit results in phosphorylation of $\mathrm{I} \kappa \mathrm{B} \alpha$ with its subsequent polyubiquitination and degradation by the $26 \mathrm{~S}$ cardiac proteasome. This releases the p65/p50 heterodimer, which translocates to the nucleus and transcribes target genes, including cytokines and cell adhesion molecules (Figure 1, A). ${ }^{8}$

We previously demonstrated that delivery of the proteasome inhibitor, PS-519, and the IKK $\beta$ inhibitor, Compound $\mathrm{A}$, at reperfusion reduced infarct size similar to delivery before injury. ${ }^{9,10}$ Yet, the mechanism of cardioprotection remains unclear. These inhibitors have different roles in the $\mathrm{NF}-\kappa \mathrm{B}$ pathway. The differences between targeting $\operatorname{IKK} \beta$, 


\section{Abbreviations and Acronyms}

ARC $=$ apoptosis repressor with caspase recruitment domain

$\mathrm{CK}-\mathrm{MB}=$ creatine kinase muscle-brain fraction

$\mathrm{I} \kappa \mathrm{B} \alpha=$ inhibitory kappa-B alpha

IKK = inhibitory kappa-B kinase

IL $\quad=$ interleukin

$\mathrm{I} / \mathrm{R}=$ ischemia/reperfusion

LAA $=$ left anterior descending

NF- $\kappa \mathrm{B}=$ nuclear factor-kappa $\mathrm{B}$

$\mathrm{TNF}=$ tumor necrosis factor a protein specific to the NF- $\kappa$ B pathway ${ }^{11}$ or the proteasome, which affects multiple pathways in the cardiomyocyte, may ultimately alter NF- $\kappa \mathrm{B}$ activity after myocardial $\mathrm{I} / \mathrm{R}$. Furthermore, the concept of delayed NF- $\kappa$ B inhibition is reasonable, because its activation occurs in mammals after ischemia for up to 4 hours. ${ }^{6,12}$ Therefore, we investigated the effect of delayed delivery (at reperfusion or 2 hours after reperfusion) of these direct and indirect inhibitors in an animal model of myocardial I/R. We proposed that inhibition of an exclusive NF- $\kappa \mathrm{B}$ pathway target, such as IKK $\beta$, would specifically interrupt NF- $\kappa$ B signaling, providing improved cardioprotection even after late administration.

\section{MATERIALS AND METHODS}

\section{Surgical Protocols}

All experimental protocols were preapproved by the University of North Carolina's Animal Care and Use Committee, and mice received humane care in compliance with the Guide for the Care and Use of Laboratory Animals. C57BL/6 mice 8 to 10 weeks of age were obtained from Charles River Laboratories (Wilmington, Mass) and housed in Division of Laboratory Animal Medicine-approved facilities with light cycling and food and water access ad libitum at least 7 days before surgery. Our experimental groups and general protocol are shown in Figure 1, B. With the animals under general anesthesia with ketamine $(100 \mathrm{mg} / \mathrm{kg})$ and xylazine $(5 \mathrm{mg} / \mathrm{kg})$ and inhaled isoflurane, myocardial I/R was induced by 30 -minute occlusion of the left anterior descending (LAD) artery using a polyethelene-10 tubing tied down to the LAD as previously described. ${ }^{10}$ After 30 minutes of ischemia, the tubing was removed. Sham animals had an air knot placed. Immediately after LAD release, the proteasome inhibitor, the IKK $\beta$ inhibitor, or a normal saline vehicle was delivered intraperitoneally to the animal. We measured infarct size in a subset of those animals and in animals given the inhibitors 2 hours after reperfusion. Infarct size was analyzed 24 hours after LAD release because gross alterations and irreversible ischemic damage occurs within the first 12 to 24 hours after ischemia. ${ }^{13}$ To analyze infarct size 24 hours after LAD occlusion, mice were reanesthetized and hearts were excised after systemic heparinization. The LAD was ligated at the same site as the previous occlusion (as noted by the suture that remained after tubing removal), and the coronary arteries were perfused with fluorescent polymer microspheres (Duke Scientific, Palo Alto, Calif) to determine the area at risk. Hearts were then serially sectioned in 1-mm intervals along the short axis and stained with $1 \%$ triphenyltetrazolium chloride to determine the area of infarct. Image $\mathbf{J}$ (National Institutes of Health, Bethesda, $\mathrm{Md}$ ) was used to calculate areas of interest.

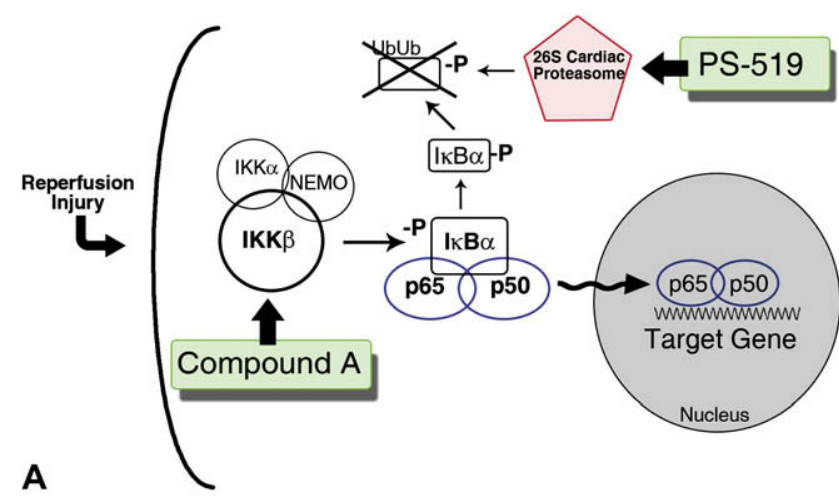

B

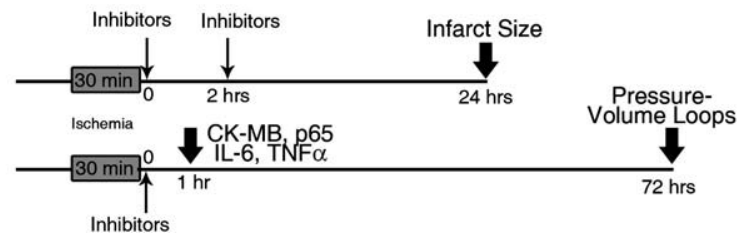

FIGURE 1. A, Diagram of $\mathrm{NF}-\kappa \mathrm{B}$ activation. Compound A inhibits the ability of $\mathrm{IKK} \beta$ to phosphorylate $\mathrm{I} \kappa \mathrm{B} \alpha$, thus preventing liberation of the p65/p50 heterodimer. PS-519 acts at the proteasome, preventing polyubiquitination and breakdown of phosphorylated $\mathrm{I} \kappa \mathrm{B} \alpha . \mathrm{B}$, Experiment design. The inhibitors, Compound A or PS-519, were given at 0 minutes or 2 hours of reperfusion, with infarct size measured 24 hours later. Separate groups of animals received the inhibitors at 0 minutes and either sacrificed at 1 hour of reperfusion for protein analysis or at 3 days for functional analysis. $I K K$, Inhibitory kappa-B kinase; $C K-M B$, creatine kinase muscle-brain fraction; $I L$, interleukin; $T N F$, tumor necrosis factor.

Functional parameters were obtained 3 days after I/R injury. Mice that had undergone in vivo $\mathrm{I} / \mathrm{R}$ and given inhibitors or vehicle at reperfusion were reanesthetized and a 1F Millar catheter (PVR-1045; Millar Instruments, Houston, Tex) was placed into the left ventricle using a closed chest technique as previously described. ${ }^{10}$ In vivo pressure-volume loops were recorded with Labview 7.1 software (National Instruments, Austin, Tex) and interpreted with PVAN (Millar Instruments). We focused on ejection fraction and $\mathrm{dP} / \mathrm{dt}$, calculated through PVAN, as measurements of myocardial function (Figure 1, B).

\section{Reagents}

The proteasome inhibitor, PS-519, was dissolved in polypropylene glycol before use and delivered at a dose of $1 \mathrm{mg} / \mathrm{kg}$ delivered intraperitoneally. This dose and method of delivery has been shown to decrease proteasome activity by approximately $80 \%$ in murine studies. ${ }^{14,15}$ Compound $\mathrm{A}$, the IKK $\beta$ inhibitor, was dissolved in $10 \%$ Cremophor in water and subsequently administered at a dose of $5 \mathrm{mg} / \mathrm{kg}$ delivered intraperitoneally. Compound $\mathrm{A}$ has been shown to have a desirable pharmacokinetic profile, ${ }^{16}$ and this dose has been effective in our previous experiments. ${ }^{10}$

\section{Serum Markers of Injury and Cytokine Expression}

A subset of mice were sacrificed 1 hour after LAD release for serum and left ventricular tissue collection. At this time, approximately $0.4 \mathrm{~mL}$ of blood was collected from animals into serum separator tubes (Becton Dickinson, Franklin Lakes, NJ) using the facial vein puncture technique. The blood was then centrifuged for 10 minutes at $2000 \mathrm{~g}$ to obtain serum. Serum creatine kinase muscle-brain fraction (CK-MB) was measured using a Vitros 250 Chemistry System (Ortho-Clinical Diagnostics, Raritan, NJ). Serum 
TABLE 1. Effects of proteasome and IKK $\beta$ inhibition on infarct size when delivered at 0 minutes or 2 hours after reperfusion

\begin{tabular}{|c|c|c|c|c|c|c|}
\hline & \multirow[b]{2}{*}{ Sham $(n=4)$} & \multirow[b]{2}{*}{ Vehicle $(n=5)$} & \multicolumn{2}{|c|}{0 min reperfusion } & \multicolumn{2}{|c|}{$2 \mathrm{~h}$ reperfusion } \\
\hline & & & $\operatorname{PS-519}(n=5)$ & $\operatorname{Comp} A(n=6)$ & $\operatorname{PS}-519(n=6)$ & $\operatorname{Comp} A(n=4)$ \\
\hline Infarct : LV (\%) & $2.3 \pm 1.3$ & $45.8 \pm 8.2^{*}$ & $24.8 \pm 3.8 \dagger$ & $25.3 \pm 3.8 \dagger$ & $31.6 \pm 1.5$ & $16.8 \pm 1.8 \dagger$ \\
\hline Infarct : AAR (\%) & $5.8 \pm 3.4$ & $70.4 \pm 2.7 *$ & $44.6 \pm 3.8 \dagger$ & $45 \pm 10.1 \dagger$ & $75.0 \pm 2.8$ & $25.9 \pm 2.5 \dagger$ \\
\hline CK-MB (U/L) $(\mathrm{n}=4)$ & $9675 \pm 608$ & $28500 \pm 2050 *$ & $12100 \pm 4096 \dagger$ & $12650 \pm 4879 \dagger$ & NA & NA \\
\hline
\end{tabular}

$L V$, Left ventricle; $A A R$, area at risk; $C K-M B$, creatine kinase muscle-brain fraction; $N A$, not available. $* P<.05$ vs sham. $\dagger P<.05$ versus vehicle.

cytokines interleukin (IL)-6 and tumor necrosis factor (TNF)- $\alpha$ were measured with respective enzyme-linked immunosorbent assay kits (R\&D Systems, Minneapolis, Minn) and quantified with a spectrophotometer (Wallac 1420 VICTOR, PerkinElmer, Waltham, Mass). Concentration of cytokines was determined according to the respective standard curve and expressed in picograms/milliliter.

\section{Left Ventricular Protein Expression}

Left ventricles obtained 1 hour after LAD release were homogenized in whole cell lysis buffer (Cell Signaling Technology, Danvers, Mass). Homogenates were then centrifuged for 30 minutes at 18,000g. The Bradford assay (Bio-Rad Laboratories, Hercules, Calif) was used to quantify protein concentration. Western blots were then run on polyvinylidene membranes as previously described. ${ }^{9}$ Membranes were incubated with phosphorylated (phospho) p65 (Ser 536), total endogenous p65 (Sigma-Aldrich, St Louis, Mo), or GAPDH (Chemicon International, Temecula, Calif) primary antibodies. Visualization of protein bands was performed with an Invitrogen kit (Invitrogen, Carlsbad, Calif), and densitometry was performed with Image $\mathbf{J}$ software.

\section{Statistical Analysis}

Comparisons between experimental infarct groups were made using 1-way analysis of variance with subsequent Dunnett's test using the statistical package Prism 4 (GraphPad, San Diego, Calif). Two-tailed Student $t$ test was used for specific comparisons between other endpoints in the experiment. Data are expressed as mean \pm standard error of the mean. Statistical significance was accepted at the $95 \%$ confidence interval.

\section{RESULTS}

\section{Temporal Differences in Proteasome and IKK $\beta$} Inhibition Affect Reperfusion Injury

Myocardial damage was assessed enzymatically 1 hour after I/R. Animals that underwent LAD occlusion followed by vehicle administration had significantly higher levels of serum CK-MB than sham animals. Compared with the vehicle group, animals that received proteasome inhibition at the time of reperfusion had significantly lower serum CK-MB levels. Similarly, IKK $\beta$ inhibition also resulted in lower serum CK-MB levels. No significant difference exists between the PS-519 group and the Compound A group (Table 1).

When administered at the time of reperfusion, both PS519 and Compound A similarly decreased infarct size compared with vehicle-treated mice. Conversely, when PS-519 and Compound $\mathrm{A}$ were delivered 2 hours after reperfusion, only IKK $\beta$ inhibition significantly reduced infarct size (Table 1).

\section{Myocardial Function Improves After Delivery of Proteasome and IKK $\beta$ Inhibitors at Reperfusion}

Pressure-volume loops recorded 3 days after I/R document the improvement of cardiac function after administration of both proteasome and IKK $\beta$ inhibitors at reperfusion. Body weight, heart rate, and left ventricular end-diastolic function were not significantly different among all groups (data not shown). Loops were shifted to the right in those animals that received vehicle, whereas proteasome and IKK $\beta$ inhibition preserved pressure-volume loops close to baseline (Figure 2, A). After I/R, animals administered vehicle had significantly lower ejection fraction and $\mathrm{dP} / \mathrm{dt}$ (Figure 2,
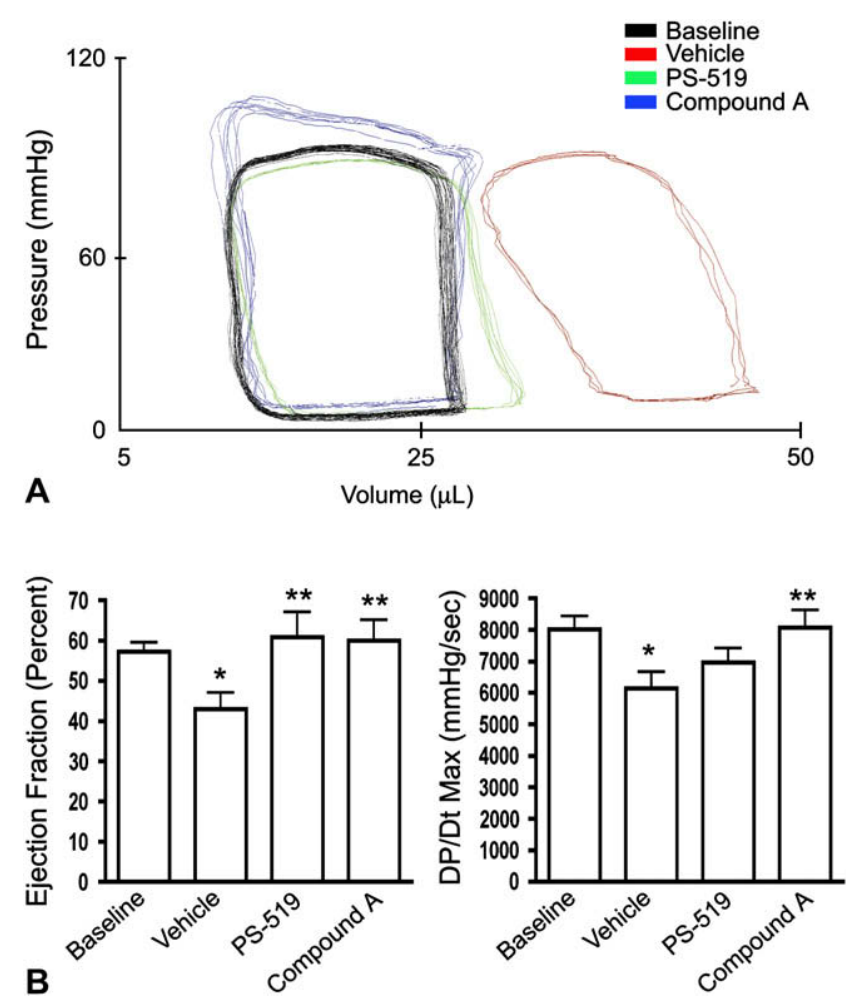

FIGURE 2. Functional assessment of cardiac reperfusion injury. A, Sample pressure-volume loops from animals administered vehicle, PS-519, or Compound $\mathrm{A}$ at 0 minutes of reperfusion and a baseline animal that had not undergone surgery. Hemodynamic parameters were measured 3 days after I/R in 4 groups of mice: baseline $(n=7)$, vehicle $(n=7), \operatorname{PS}-519(n=$ $7)$, and Compound A $(n=5)$. B, Mice treated with proteasome and IKK $\beta$ inhibitors at reperfusion had improved function as measured by ejection fraction; however, proteasome inhibition failed to significantly preserve $\mathrm{dP} / \mathrm{dt} . * P<.05$ versus baseline. $* * P<.05$ versus vehicle. 

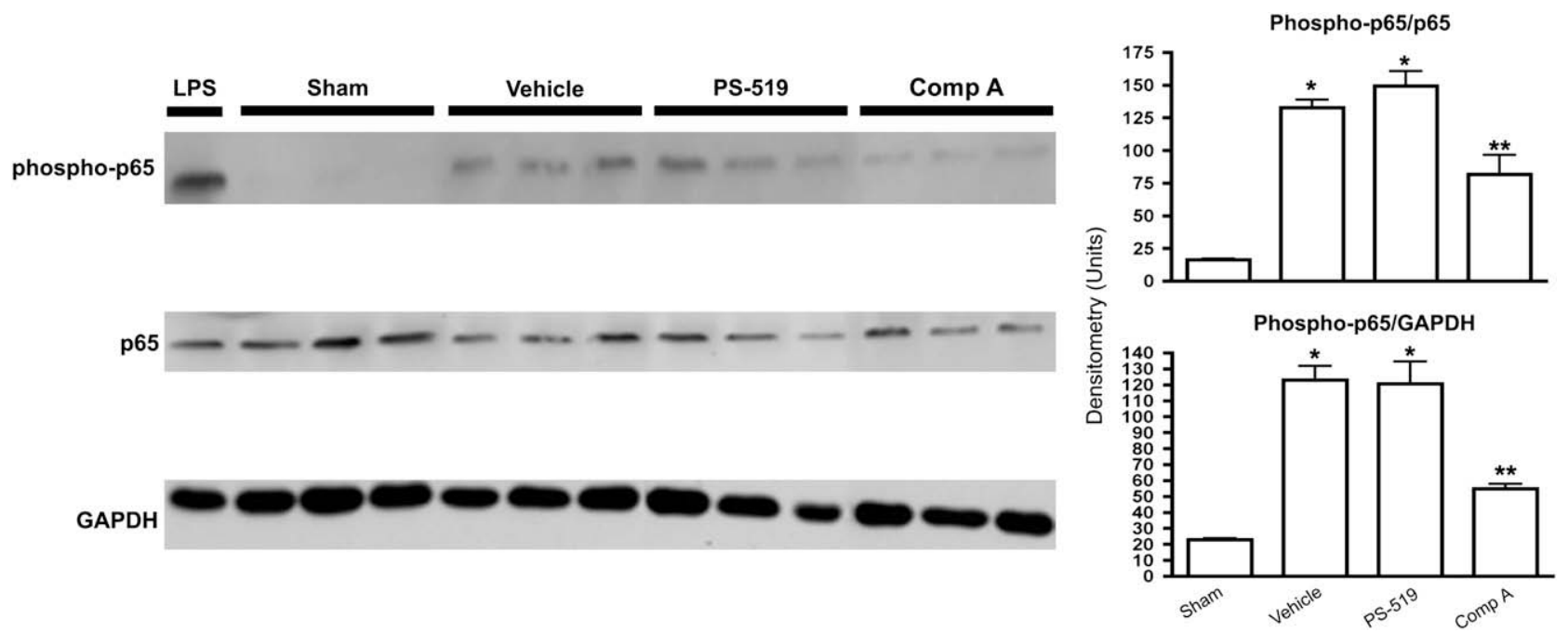

FIGURE 3. Myocardial NF- $\kappa$ B activation after reperfusion. Expression of the NF- $\kappa$ B subunit, p65, as well as its activated form, phosphorylated-p65, was analyzed in left ventricular homogenates 1 hour after treatment at 0 minutes of reperfusion. A mouse administered lipopolysaccharide (LPS), a potent stimulant of NF- $\kappa \mathrm{B}$, is a positive control for p65 phosphorylation. GAPDH serves as a loading control. Densitometry was performed, and the ratios of phospho-p65 to 655 and phosph-p65 to GAPDH are graphically represented. $\mathrm{N}=3$ for sham, vehicle, PS-519, and Compound A groups. $* P<.05$ versus sham. $* * P<.05$ versus vehicle. $L P S$, lipopolysaccharide; GAPDH, glyceraldehyde-3-phosphate dehydrogenase.

$B$ ) than mice without I/R injury. Proteasome and IKK $\beta$ inhibition delivered after acute $\mathrm{I} / \mathrm{R}$ maintained ejection fraction similar to baseline levels. On analysis of $\mathrm{dP} / \mathrm{dt}$, a parameter that is less load-dependent and more indicative of myocardial contractility than ejection fraction, ${ }^{17}$ only IKK $\beta$ inhibition provided significant functional protection above the vehicle group. This suggests that although both inhibitors allow for recovery of global left ventricular function after reperfusion, inhibition of IKK $\beta$ better protects from intrinsic contractile dysfunction after I/R.

\section{Delayed IKK $\beta$ Inhibition, but not Proteasome Inhibition, Decreases Expression of NF- $\kappa$ B}

The expression pattern of p65 and phospho-p65, the activated subunit of the $\mathrm{NF}-\kappa \mathrm{B}$ heterodimer, was determined in heart tissue 1 hour after reperfusion injury. The ratio of phospho-p65 to both endogenous p65 and GAPDH was significantly elevated in the animals that received vehicle at the onset of reperfusion compared with sham animals. Expression of phospho-p65 was significantly attenuated in animals treated with the IKK $\beta$ inhibitor, Compound A. Proteasome inhibition, however, did not result in decreased phospho-p65 expression compared with vehicle animals (Figure 3).

\section{Cytokines Attenuated by IKK $\beta$ Inhibition, but not Proteasome Inhibition}

Serum cytokines TNF- $\alpha$ and IL- 6 in animals that received vehicle were significantly elevated compared with the sham group (Figure 4). After administration of Compound A at
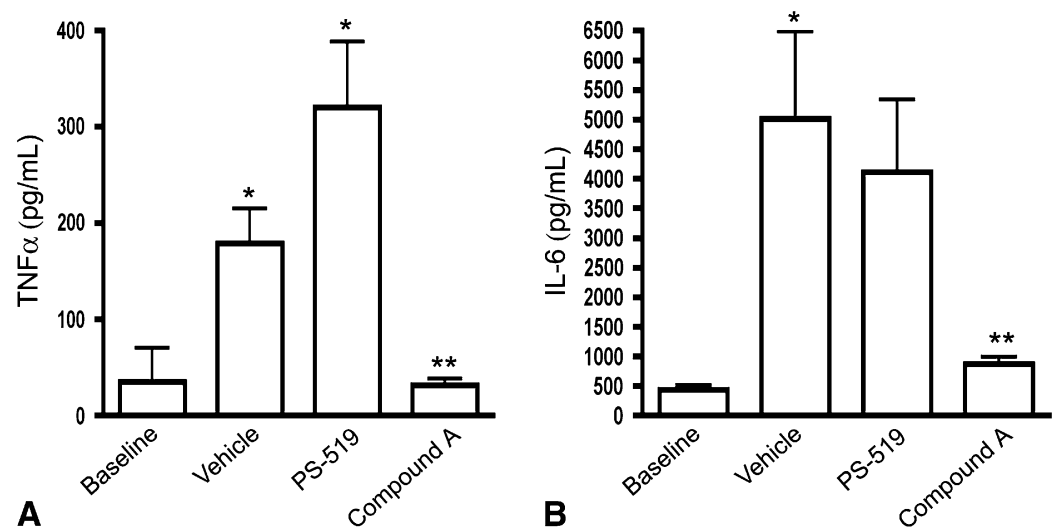

FIGURE 4. NF- $\kappa$ B-related cytokine expression. Serum cytokines TNF- $\alpha$ (A) and IL-6 (B) in animals treated with PS-519 and Compound A after reperfusion. TNF- $\alpha$ : sham $\mathrm{n}=3$; vehicle $\mathrm{n}=6$; PS-519, Compound A $\mathrm{n}=4$. IL-6: sham, PS-519, Compound A $\mathrm{n}=4$; vehicle $\mathrm{n}=7$. $* P<.05$ versus sham. $* * P<$ .05 versus vehicle. $T N F$, Tumor necrosis factor. 
reperfusion, the levels of TNF- $\alpha$ and IL- 6 were significantly attenuated compared with vehicle. Proteasome inhibition did not decrease TNF- $\alpha$, but rather increased it significantly above sham levels, with a trend suggesting TNF- $\alpha$ levels were higher than vehicle.

\section{DISCUSSION}

When delivered at reperfusion in a murine model of myocardial I/R, both IKK $\beta$ and proteasome inhibition decrease infarct size, attenuate CK-MB levels, and preserve ejection fraction. Our results indicate, however, that the cardioprotective mechanism of delayed proteasome inhibition is independent of the NF- $\kappa$ B signaling pathway. Only the specific IKK $\beta$ inhibitor prevents phosphorylation of p65 and downstream cytokine expression of IL- 6 and TNF- $\alpha$ when administered at reperfusion. This may contribute to the inability of PS-519 to reduce infarct size, compared with Compound A, when delivered 2 hours after LAD release.

This is an important observation in the context of transforming basic science findings into daily clinical practice. For various cancer models, NF- $\kappa \mathrm{B}$ inhibitors, including proteasome inhibitors, have successfully translated from the cell and animal model to human clinical trials. ${ }^{18}$ The introduction of specific NF- $\kappa$ B inhibitors for cardioprotection, however, has failed to materialize. Matsuki and colleagues ${ }^{19}$ recently described the cardioprotective effects of fluvastatin when administered to rats 2 weeks before $\mathrm{I} / \mathrm{R}$. However, the beneficial effects of this statin were lost on delivery at the time of ischemia or the start of reperfusion. Furthermore, the mechanism of protection was not mediated via antioxidant properties as expected, but via increased nitric oxide production. The proteasome inhibitor, like fluvastatin, can alter several pathways activated after myocardial $\mathrm{I} / \mathrm{R}$. Although PS-519 decreased infarct size in our model of myocardial $\mathrm{I} / \mathrm{R}$ when administered after ischemia, the mechanism is not NF- $\kappa \mathrm{B}$ mediated. Furthermore, any cardioprotective effects of proteasome inhibition were lost after late delivery 2 hours after myocardial reperfusion. Therapeutic timing is a critical determinant of mechanism, therefore, especially regarding relatively nonspecific targets, such as the cardiac proteasome, that can ultimately modify multiple cellular mechanisms.

We previously demonstrated that delivery of PS-519 before myocardial $\mathrm{I} / \mathrm{R}$ was cardioprotective through inhibition of NF- $\kappa$ B. ${ }^{6,9}$ The results of this study demonstrate, however, that proteasome antagonism immediately after ischemia does not attenuate phosphorylated-p65 levels or downstream cytokines regulated by NF- $\kappa \mathrm{B}$. Rather the decrease in myocardial damage at this time point could be mediated through other proteasome-regulated pathways. Part of the ubiquitinproteasome system, the proteasome regulates the proteolysis and elimination of proteins involved in myriad cellular mechanisms, from apoptosis and differentiation to inflammation and proliferation. ${ }^{20}$ For example, destabilization of the apoptosis inhibitor, apoptosis repressor with caspase recruitment domain (ARC), after oxidative stress is mediated by the ubiquitin-proteasomal pathway. ${ }^{21}$ Although ARC is expressed at the start of reperfusion in mouse models of myocardial I/R, its expression is minimal 2 hours after reperfusion. ${ }^{21}$ Proteasome inhibition at the onset of reperfusion may prevent the destabilization of ARC, protecting myocardium from reperfusion-induced apoptosis. In fact, ARCdeficient mice had 50\% larger infarcts after myocardial $\mathrm{I} / \mathrm{R}$ than their wild-type controls. ${ }^{22}$ In addition to altering apoptotic pathways, proteasome inhibition has also been shown to induce heat-shock proteins in cardiomyocytes, conferring protection after oxidative stress. ${ }^{23,24}$ Thus the effects of proteasome inhibition can be multifactorial and are not restricted to the NF- $\kappa \mathrm{B}$ pathway alone.

Unlike the proteasome, IKK $\beta$ is specific to the NF- $\kappa \mathrm{B}$ pathway. IKK $\beta$ knockout mice die in utero of liver failure from massive hepatocyte apoptosis and have complete disruption of the NF- $\kappa \mathrm{B}$ signaling pathway. ${ }^{25}$ Pharmacologic inhibition of IKK $\beta$ with Compound $\mathrm{A}$ is a specific process that directly prevents the phosphorylation of the NF- $\kappa$ B repressor protein, $\mathrm{I} \kappa \mathrm{B} \alpha$. Downstream expression of phosphorylated p65 and cytokines IL- 6 and TNF- $\alpha$ is repressed after administration of Compound A. This pattern of NF- $\kappa$ B disruption is similar when IKK $\beta$ is inhibited before ${ }^{10}$ and after the period of cardiac ischemia. Furthermore, IKK $\beta$ inhibition appears to be even more effective after 2 hours of reperfusion. Late protection is rational, because previous studies have documented the persistence of NF- $\kappa$ B levels for several hours after reperfusion. ${ }^{26,27}$ Although this smaller infarct size is not significantly different from delivery at reperfusion, this trend emphasizes the distinct advantage specific $\mathrm{NF}-\kappa \mathrm{B}$ inhibition through the IKK $\beta$ subunit provides in a late setting compared with the relatively nonspecific proteasome.

\section{CONCLUSIONS}

Despite 3 decades of research investigating methods to reduce myocardial reperfusion injury, few experimental therapies have translated successfully to our patients. Although hundreds of pharmacologic inhibitors have been tested in animal models of I/R, our review reveals a dearth of studies that have focused on delayed interventional therapies for cardiac reperfusion injury. To our knowledge, this is the first study both directly comparing 2 applicable NF- $\kappa$ B inhibitors and investigating delayed delivery of NF- $\kappa \mathrm{B}$ inhibition after the reperfusion event has occurred. This approach is especially important, because successful NF- $\kappa \mathrm{B}$-mediated cardioprotection is not only temporally dependent but also dependent on the specificity of the mechanism of NF- $\kappa$ B inhibition.

The authors thank Peter Charles, $\mathrm{PhD}$, for statistical assistance and Margaret Cloud for editorial assistance. 


\section{References}

1. Meldrum DR, Partrick DA, Cleveland JC Jr, Shenkar R, Meldrum KK, Raiesdana A, et al. On-pump coronary artery bypass surgery activates human myocardial NF-kappaB and increases TNF-alpha in the heart. J Surg Res. 2003;112:175-9.

2. Li C, Ha T, Liu L, Browder W, Kao RL. Adenosine prevents activation of transcription factor NF-kappa B and enhances activator protein-1 binding activity in ischemic rat heart. Surgery. 2000;127:161-9.

3. Jancso G, Cserepes B, Gasz B, Benko L, Ferencz A, Borsiczky B, et al. Effect of acetylsalicylic acid on nuclear factor-kappaB activation and on late preconditioning against infarction in the myocardium. J Cardiovasc Pharmacol. 2005;46: 295-301.

4. Planavila A, Laguna JC, Vazquez-Carrera M. Atorvastatin improves peroxisome proliferator-activated receptor signaling in cardiac hypertrophy by preventing nuclear factor-kappa B activation. Biochim Biophys Acta. 2005;1687:76-83.

5. Morishita R, Sugimoto T, Aoki M, Kida I, Tomita N, Moriguchi A, et al. In vivo transfection of cis element "decoy" against nuclear factor-kappaB binding site prevents myocardial infarction. Nat Med. 1997;3:894-9.

6. Pye J, Ardeshirpour F, McCain A, Bellinger DA, Merricks E, Adams J, et al. Proteasome inhibition ablates activation of NF-kappa B in myocardial reperfusion and reduces reperfusion injury. Am J Physiol Heart Circ Physiol. 2003;284: H919-26.

7. Bolli R, Becker L, Gross G, Mentzer R Jr, Balshaw D, Lathrop DA. Myocardial protection at a crossroads: the need for translation into clinical therapy. Circ Res. 2004;95:125-34.

8. Valen G, Yan ZQ, Hansson GK. Nuclear factor kappa-B and the heart. J Am Coll Cardiol. 2001;38:307-14.

9. Stansfield WE, Moss NC, Willis MS, Tang R, Selzman CH. Proteasome inhibition attenuates infarct size and preserves cardiac function in a murine model of myocardial ischemia-reperfusion injury. Ann Thorac Surg. 2007;84:120-5.

10. Moss NC, Stansfield WE, Willis MS, Tang RH, Selzman CH. IKKbeta inhibition attenuates myocardial injury and dysfunction following acute ischemia-reperfusion injury. Am J Physiol Heart Circ Physiol. 2007;293:H2248-53.

11. Elliott PJ, Zollner TM, Boehncke WH. Proteasome inhibition: a new anti-inflammatory strategy. J Mol Med. 2003;81:235-45

12. Yeh $\mathrm{CH}$, Chen TP, Wu YC, Lin YM, Jing Lin P. Inhibition of NFkappaB activation with curcumin attenuates plasma inflammatory cytokines surge and cardiomyocytic apoptosis following cardiac ischemia/reperfusion. J Surg Res. 2005; 125:109-16.

13. Jugdutt BI. Ventricular remodeling after infarction and the extracellular collagen matrix: when is enough enough? Circulation. 2003;108:1395-403.

14. Zollner TM, Podda M, Pien C, Elliott PJ, Kaufmann R, Boehncke WH. Proteasome inhibition reduces superantigen-mediated $\mathrm{T}$ cell activation and the severity of psoriasis in a SCID-hu model. J Clin Invest. 2002;109:671-9.

15. Shah IM, Lees KR, Pien CP, Elliott PJ. Early clinical experience with the novel proteasome inhibitor PS-519. Br J Clin Pharmacol. 2002;54:269-76.

16. Ziegelbauer K, Gantner F, Lukacs NW, Berlin A, Fuchikami K, Niki T, et al. A selective novel low-molecular-weight inhibitor of IkappaB kinase-beta (IKKbeta) prevents pulmonary inflammation and shows broad anti-inflammatory activity. Br J Pharmacol. 2005;145:178-92.

17. McGinley JC, Berretta RM, Chaudhary K, Rossman E, Bratinov GD, Gaughan JP, et al. Impaired contractile reserve in severe mitral valve regurgitation with a preserved ejection fraction. Eur J Heart Fail. 2007;9:857-64.

18. Milano A, Iaffaioli RV, Caponigro F. The proteasome: a worthwhile target for the treatment of solid tumours? Eur J Cancer. 2007;43:1125-33.

19. Matsuki A, Igawa A, Nozawa T, Nakadate T, Igarashi N, Nonomura M, et al. Early administration of fluvastatin, but not at the onset of ischemia or reperfusion, attenuates myocardial ischemia-reperfusion injury through the nitric oxide pathway rather than its antioxidant property. Circ J. 2006;70:1643-9.

20. Willis MS, Patterson C. Into the heart: the emerging role of the ubiquitin-proteasome system. J Mol Cell Cardiol. 2006;41:567-79.

21. Nam YJ, Mani K, Wu L, Peng CF, Calvert JW, Foo RS, et al. The apoptosis inhibitor ARC undergoes ubiquitin-proteasomal-mediated degradation in response to death stimuli: identification of a degradation-resistant mutant. J Biol Chem 2007;282:5522-8.

22. Donath S, Li P, Willenbockel C, Al-Saadi N, Gross V, Willnow T, et al. Apoptosis repressor with caspase recruitment domain is required for cardioprotection in response to biomechanical and ischemic stress. Circulation. 2006;113: 1203-12.

23. Stangl K, Gunther C, Frank T, Lorenz M, Meiners S, Ropke T, et al. Inhibition of the ubiquitin-proteasome pathway induces differential heat-shock protein response in cardiomyocytes and renders early cardiac protection. Biochem Biophys Res Commun. 2002;291:542-9.

24. Luss H, Schmitz W, Neumann J. A proteasome inhibitor confers cardioprotection. Cardiovasc Res. 2002;54:140-51.

25. Li ZW, Chu W, Hu Y, Delhase M, Deerinck T, Ellisman M, et al. The IKKbeta subunit of IkappaB kinase (IKK) is essential for nuclear factor kappaB activation and prevention of apoptosis. $J$ Exp Med. 1999;189:1839-45.

26. Kin H, Wang NP, Halkos ME, Kerendi F, Guyton RA, Zhao ZQ. Neutrophil depletion reduces myocardial apoptosis and attenuates NFkappaB activation/ TNFalpha release after ischemia and reperfusion. J Surg Res. 2006;135: 170-8.

27. Kis A, Yellon DM, Baxter GF. Role of nuclear factor-kappa B activation in acute ischaemia-reperfusion injury in myocardium. $\mathrm{Br} J$ Pharmacol. 2003;138: 894-900.

\section{DISCUSSION}

Dr Frank Sellke (Boston, Mass). That was a nice study. My question is kind of generic. You mentioned in the beginning of your talk that there have been approximately 10,000 studies showing benefit in laboratory animals, yet when it goes to the clinic, very few, if any, really show any promise. Why is that?

Dr Moss. Well, I think there are many factors. One is timing. It is really surprising, but actually when you start reading all of those studies, you will find that the majority of inhibitors are given before ischemia or during ischemia, a time for us that isn't clinically relevant. You can't really pinpoint what is going to happen during that time, and the time of reperfusion, when the stent is placed or when you come off clamp, is the one thing that we do know. Unfortunately, temporally relevant conditions haven't really been studied that much, and so that was one of the points of this article. It is almost more conceptual, I think. The point of this article is that we really need to pin down exactly what we are translating into clinical practice, because it may not work if you do it a different way in those animal studies.

Then also, for example, one limitation of this study is that these are healthy 8-week-old C57 black six mice. These aren't knockout or like apolipoprotein E, and they develop atherosclerosis like you might find in the person undergoing CABG. They are not obese or diabetic. I think we need to have more studies that look at a multifactorial animal, because it may not work. Although it might work in a healthy animal, it may not work in one that is diabetic or has other comorbidities. 